\title{
Influence of the pyrolysis heating rate on the steam gasification rate of large wood char particles
}

\author{
F. Mermoud ${ }^{\text {a, } *}$, S. Salvador ${ }^{\text {b }}$, L. Van de Steene ${ }^{\text {a }}$, F. Golfier $^{c}$ \\ ${ }^{\text {a } C I R A D-F o r e ̂ t, ~ T A ~ 10 / 16, ~} 73$ Rue JF Breton, 34398 Montpellier Cedex 5, France \\ ${ }^{\mathrm{b}}$ LGPSD, UMR 2392 CNRS, Ecole des Mines d'Albi-Carmaux, Route de Teillet, 81013 ALBI CT Cedex 09, France \\ ${ }^{\mathrm{c}}$ LAEGO-ENSG-INPL, Rue du doyen Marcel Roubault, BP 40, 54501 Vandoeuvre-les-Nancy, France
}

\begin{abstract}
This work was carried out in order to quantify the impact of the pyrolysis heating rate both on the properties of the residual charcoal and on the behaviour during gasification by $\mathrm{H}_{2} \mathrm{O}$ of the charcoal. The experiments were conducted on $10 \mathrm{~mm}$ diameter beech wood spheres, pyrolysed at atmospheric pressure under heating rates covering the range from very slow, $2.6 \mathrm{~K} \mathrm{~min}^{-1}$, to very rapid, over $900 \mathrm{~K} \mathrm{~min}^{-1}$, i.e. the highest value that can be reached. When charcoal is submitted to gasification at $20 \% \mathrm{H}_{2} \mathrm{O}$ i nN 2 at $1200 \mathrm{~K}$, the ratio of the times for complete conversion reach 2.6. Such a difference is considerable as far as an industrial application is concerned. The initial properties of the charcoal such as apparent density, porosity, and pore surface area obtained by $\mathrm{N}_{2}$ or Ar adsorption were measured in order to explain the differences in gasification kinetics within the charcoal. The charcoal particles exhibit densities as different as $219-511 \mathrm{~kg} \mathrm{~m}^{-3}$ and porosities between 87 and $70 \%$ for charcoal prepared at 900 and $2.6 \mathrm{~K} \mathrm{~min}^{-1}$ respectively. The specific surface area is higher than $600 \mathrm{~m}^{2} \mathrm{~g}^{-1}$ for three charcoals. Influence of ash content of the initial charcoals, at $1.6-2.7 \%$, is also regarded with particular attention to explain the observed differences in gasification kinetics.
\end{abstract}

\section{Introduction}

The conversion of solid biomass products into high calorific value gases is one of the most interesting ways to convert solar energy into mechanical and electrical energy. A variety of processes have been developed over the past decades to achieve this conversion, termed gasification. Fixed bed reactors, fluidised bed reactors or flash processes are the most common techniques.

Whatever be the process used, it is admitted that the biomass will go through at least the following transformations: at temperatures between 300 and $500 \mathrm{~K}$, the biomass is dried; when the temperature reaches $600 \mathrm{~K}$ approximately, thermal cracking occurs, during which volatile matters (VM) are released and a solid carbonaceous residue, called charcoal, is formed, this transformation is termed pyrolysis or devolatilisation; finally, gasification of the solid charcoal residue, involving heterogeneous reactions, occurs in an oxidising

\footnotetext{
* Corresponding author.Tel.: +3346761 58 43; fax: +33467616515. E-mail address: mermoud@cirad.fr (F. Mermoud).
}

atmosphere such as $\mathrm{O}_{2}, \mathrm{H}_{2} \mathrm{O}$ or $\mathrm{CO}_{2}$, at higher temperatures, typically $1000-1600 \mathrm{~K}$.

Gasification by $\mathrm{H}_{2} \mathrm{O}$ is regarded with particular interest for two reasons. Firstly, the gases formed, $\mathrm{H}_{2}$ and $\mathrm{CO}$, present a high calorific value compared to $\mathrm{CO}_{2}$ and $\mathrm{CO}$ formed during combustion with $\mathrm{O}_{2}$, or $\mathrm{CO}$ formed during $\mathrm{CO}_{2}$ gasification. Secondly, the reaction is much more rapid using $\mathrm{H}_{2} \mathrm{O}$ rather than $\mathrm{CO}_{2}$ as an oxidant. For instance, in the case of wood char, reaction is 2-5 times more rapid according respectively to [1,2]; for coal, it is $2-3$ times more rapid [3,4].

Operating conditions during pyrolysis — such as heating rate (HR, in $\mathrm{K} \mathrm{min}^{-1}$ ), final temperature, residence time, pressure or size of the particles - are known to have an influence on the morphology of the charcoal obtained, as well as on its reactivity during gasification.

Kumar and Gupta [5] observed that an increase of the final pyrolysis temperature-from 1073 to $1473 \mathrm{~K}$-decreases charcoal reactivity to $\mathrm{CO}_{2}$ gasification. This suggests that a higher pyrolysis temperature enables a better structural ordering of the carbon matrix, with a lower concentration of active sites available for reaction.

The soaking time at final pyrolysis temperature is known to have a negative influence on the reactivity of the charcoal. 


\begin{tabular}{|c|c|c|c|}
\hline \multicolumn{4}{|c|}{ Nomenclature } \\
\hline [Ash] & ash fraction in the carbon matrix ( $g_{\text {ash }} g_{\text {char }}^{-1}$ ) & $m_{\mathrm{ash}}$ & ash mass $(g)$ \\
\hline HR & heating rate $\left(\mathrm{K}_{\min }^{-1}\right)$ & $m_{\text {init }}$ & initial sample mass $(g)$ \\
\hline$k_{\text {app }}$ & apparent kinetics constant or apparent reactivity & $S_{\mathrm{r}}$ & reactive surface $\left(\mathrm{m}^{2} \mathrm{~g}^{-1}\right)$ \\
\hline & $\left(s^{-1}\right)$ & $t$ & time $(s)$ \\
\hline$k a_{\text {int }}$ & intrinsic kinetics constant relative to the ash & VM & volatile matters (wt\%) \\
\hline & fraction $\left(g_{\text {char }} g_{\text {ash }}^{-1} s^{-1}\right)$ & $X$ & conversion \\
\hline$k s_{\text {int }}$ & intrinsic kinetics constant relative to the reactive & $\varepsilon$ & porosity (v\%) \\
\hline & surface $\left(\mathrm{g} \mathrm{s}^{-1} \mathrm{~m}^{-2}\right)$ & $\rho_{\text {solid }}$ & density of the solid phase $\left(\mathrm{kg} \mathrm{m}^{-3}\right)$ \\
\hline$m$ & sample mass at time $t(g)$ & $\rho_{\text {apparent }}$ & apparent density $\left(\mathrm{kg} \mathrm{m}^{-3}\right)$ \\
\hline
\end{tabular}

This phenomenon is called thermal annealing or thermal deactivation in the sequel of the paper. Walker [6], considering coal gasification in air, explained thermal annealing by a phenomenon of sintering of the minerals present in the charcoal. Dispersion of the minerals in the charcoal, which act as a catalyst for the reaction, is then decreased and the catalyst activity is lowered.

Roberts et al. [7] studied the effect of pressure-from 1 to $15 \mathrm{~atm}$-during pyrolysis of several coals on the reactivity of charcoal with $\mathrm{CO}_{2}$ and $\mathrm{H}_{2} \mathrm{O}$, and observed that a higher pyrolysis pressure yields a more reactive charcoal, with a larger surface area. They suggested that a high pressure could produce large void areas in the charcoal, increasing the accessible porosity for the reaction and then the charcoal reactivity.

The size of the wood particles is a determining parameter throughout the pyrolysis process. At first, due to heat transfer limitations, the heating rate at various positions along a radius inside a particle is different. Secondly, the residence time of evolved volatile matters and tars depends on the radius of the particle; the deposition of pyrolytic carbon is affected by this parameter.

It is clearly established today that pyrolysis HR has an impact on the total volatile matter yield, its chemical composition [8-12] and on the structural properties of the charcoal produced. Numerous authors [5-7,11,13,14] agree that the pyrolysis HR of the initial biomass significantly influences the reactivity of the charcoal during its gasification. Higher HR were found to provide more reactive charcoals during gasification by $\mathrm{CO}_{2}[5,7,13]$ or $\mathrm{H}_{2} \mathrm{O}[7,11]$. Even if most of the authors attribute this behaviour to structural properties of charcoal, explanation remains subject to discussion. Kumar and Gupta [5] explain that at high HR conditions, both a lower amount of deposit of pyrolytic carbon-which retards reactivity-and a carbon matrix with defective microcrystallites-which provide a higher concentration of active site-are responsible for the higher reactivity of charcoal during gasification.

It is today acknowledged that a high pyrolysis HR yields more VM than a low pyrolysis HR, and that these VM mainly consist of heavy compounds, with a high $\mathrm{C} / \mathrm{H}$ ratio. Indeed, a high HR leads to a rapid formation of VM causing a rapid increase of pressure in the wood particle and an explosive release of gases. On the contrary, a low HR enables an

extended residence time of the volatiles in the particle, increasing the occurrence of repolymerisation of the volatiles inside the charcoal. These secondary reactions take place upon contact with the charcoal and generate lighter compoundswith a lower $\mathrm{C} / \mathrm{H}$ ratio, re-forming charcoal at the surface of the solid. The char yield is then increased compared to a rapid pyrolysis.

Despite the fact that charcoals are all essentially made of carbon, the reactivity during gasification of charcoals from different origins can vary in a range of several orders of magnitude. Numerous authors are looking for an explanation in terms of a reactive surface. For Roberts et al. [7], reaction of charcoals with $\mathrm{CO}_{2} / \mathrm{H}_{2} \mathrm{O}$ uses and develops the micropore surface area, unlike char- $\mathrm{O}_{2}$ reaction. On the contrary, Fushimi et al. [11] explained that macropores, because of their accessibility to the reactants, are supposed to provide more active sites than micropores, which seem to hardly participate in the reaction; the difference in reactivities observed is explained by the difference in macropore surface area. This conclusion is in accordance with work by Cetin et al. [13], who showed that high HR charcoals mainly consist of macropores. However, the determination of a reactive surface remains a difficult task. The values obtained for the total pore surface area sometimes depends on the technique used, such as $\mathrm{N}_{2}$, Ar or $\mathrm{CO}_{2}$ adsorption or $\mathrm{Hg}$ intrusion, which raises here numerous questions. An attempt is made later in this work to identify a reactive surface area that can be correlated with the reactivity of the charcoals. The gasification process is known to be very complex since lots of phenomena take place together and also because fracturation can occur, possibly increasing the reactivity by facilitating the diffusion of the reactants inside the particle.

In many processes, the transformations of pyrolysis and gasification take place inside the same reactor. In other processes, called staged gasifiers, pyrolysis is realised in a separate reactor. This enables better control of the process, giving the option of acting separately on the two transformations. The impact of the pyrolysis HR on the gasification kinetics is especially important for the design of staged gasifiers. Gasification of charcoals by $\mathrm{CO}_{2}$ was widely studied in previous works $[1,5,7,13,15-19]$, but only a few authors worked on steam gasification $[11,12,17,20]$, although it is the preponderant reaction in industrial applications. The present work was carried out in order to contribute to the understanding 
of process size particles pyrolysis, and the impact of this treatment on the following gasification by $\mathrm{H}_{2} \mathrm{O}$. In other words, an attempt is made to answer to the following questions:

(i) what are the structural properties of the charcoals obtained after pyrolysis in different conditions of HR?

(ii) what is the impact of the pyrolysis $\mathrm{HR}$ on the behaviour of the charcoal when submitted to gasification by $\mathrm{H}_{2} \mathrm{O}$ ?

(iii) is it possible to link measured properties of a charcoal to its behaviour during gasification?

\section{Pyrolysis at different heating rates and properties of the charcoals}

\subsection{Pyrolysis experiments}

Wood is a good material to represent biomass products. In an industrial fixed bed, the size of the wood chips is typically up to several centimetres. The smaller dimension is typically around $1 \mathrm{~cm}$; this characteristic size was retained for the present work. Beech wood spheres calibrated at a 10.2 \pm $0.1 \mathrm{~mm}$ diameter were used in order to eliminate the potential effect on the results of changes in the geometry of the particles from one experiment to another. The proximate and ultimate analysis on dry basis of the initial wood, reported in Table 1, were measured in compliance with standards NF-M03-003 and NF-B55-101. The volatile matter percentage is as high as $82 \%$, and the ash content of the wood is low: $0.38 \%$.

In this work, the choice for the range of studied HR was realised as follows. The lower value for the HR$2.6 \mathrm{~K} \mathrm{~min}^{-1}$ - is very low compared to an industrial process, corresponding to heating to $773 \mathrm{~K}$ in more than $3 \mathrm{~h}$. The value of $900 \mathrm{~K} \mathrm{~min}^{-1}$ is the most rapid heating that can be operated on such particles, as explained below. Such high values can be encountered in an industrial process in the case where a particle enters into contact with a heated wall or is in a fluidised bed. The intermediate value of $12 \mathrm{~K} \mathrm{~min}^{-1}$ corresponds to heating to $773 \mathrm{~K}$ within approximately $40 \mathrm{~min}$; it is close to typical values in an industrial process. The extremely high HR such as $10^{5} \mathrm{~K} \mathrm{~s}^{-1}$, commonly studied, were not taken into account in this study, because not reachable with particles greater than about $0.1 \mathrm{~mm}$ diameter [21].

Pyrolysis at 2.6 and $12 \mathrm{~K} \mathrm{~min}^{-1}$ was carried out in a muffle furnace; the wood particles were placed in a refractory steel

Table 1

Analysis of the initial beech wood samples

\begin{tabular}{lr}
\hline Proximate analysis (wt $\%)$ & \\
Ash & 0.38 \\
Volatile matters & 82.45 \\
Fixed carbon (by difference) & 17.17 \\
Ultimate analysis (wt\%) & \\
C & 44.16 \\
H & 5.48 \\
O (by difference) & 50.36 \\
\hline
\end{tabular}

box swept with nitrogen. The temperature was increased at the controlled HR from room temperature to $1073 \mathrm{~K}$. The furnace was kept 1 at this temperature and then stopped before cooling the sample with nitrogen. It is likely that complete pyrolysis was achieved before the temperature of $1073 \mathrm{~K}$ was reached [16], as observed in the preparation of our charcoal samples.

The high HR was achieved using the 'macro-TG' apparatus described further (cf. Fig. 1), with $\mathrm{N}_{2}$ as the atmosphere gas. The reactor and atmosphere gas were heated at $1200 \mathrm{~K}$; when the temperature was stabilised, seven wood particles, not in contact, held on a flat basket consisting of a refractory steel grid-were lifted and hanged on the precision load cell. The evolution of the normalised mass of the seven particles showed

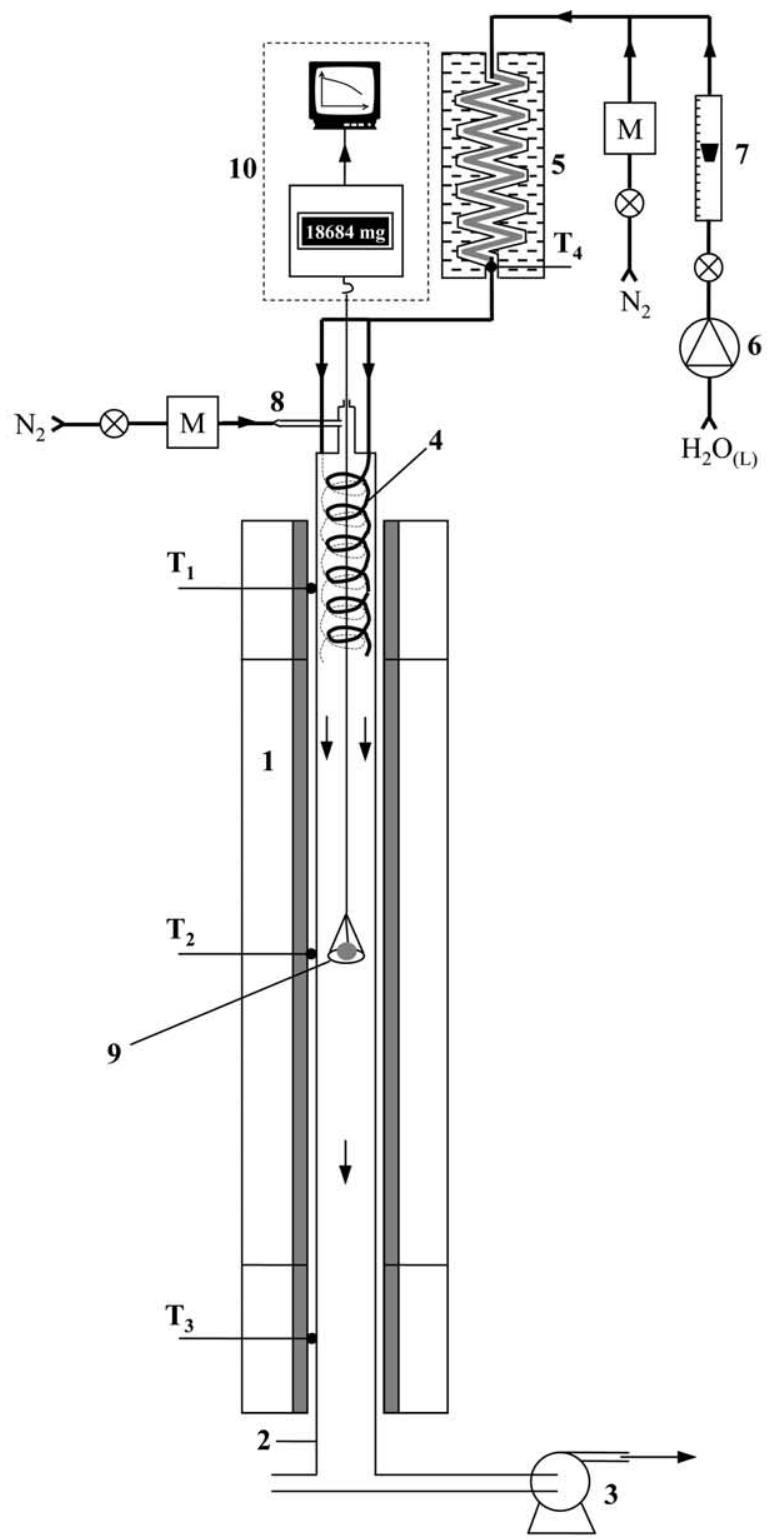

(1) Electrical furnace (2) Quartz tube (3) Extractor (4) Preheater (5) Evaporator (electrically heated) (6) Peristaltic pump (7) Variable area flowmeter (8) Leak flow compensator (9) Hanging mechanism (10) Weighing/Recording device ( $\left.T_{i}\right)$ Regulation thermocouple (M) Mass flowmeter/controller

Fig. 1. Macro-TG experimental apparatus. 
that almost complete pyrolysis was achieved within $1 \mathrm{~min}$. For this reason, we considered that the global HR of the particles, that were probably not isothermal, was greater than $900 \mathrm{~K} \mathrm{~min}^{-1}$. The wood particles were kept under nitrogen during $8 \mathrm{~min}$ in order to assure complete pyrolysis before feeding steam and beginning the gasification of the charcoal particles.

\subsection{Characterisation of the charcoals}

Size and mass of the charcoal particles obtained after pyrolysis at $\mathrm{HR}$ of $2.6,12$ and $900 \mathrm{~K} \mathrm{~min}^{-1}$ were precisely measured; their apparent densities were then calculated (cf. Table 2). We observed that the original wood spheres got an ovoid shape after pyrolysis. The projected surround in the three directions was an ellipse, resulting from the non-isotropic properties of wood. The equivalent sphere diameter was calculated as the average of three different dimensions (cf. Table 2). It is interesting to note that the size of the particles is similar for pyrolysis at 2.6 and $12 \mathrm{~K} \mathrm{~min}^{-1}$; it is a bit higher in the case of high HR. It can be noted that the charcoal particles volume is approximately three times smaller than that of the initial particles. Nevertheless, no cracks could be observed at the surface of the charcoal particles.

Very important differences in the charcoal apparent densities $\rho_{\text {apparent }}$ were observed: $511 \mathrm{~kg} \mathrm{~m}^{-3}$ for charcoal obtained at $2.6 \mathrm{~K} \mathrm{~min}^{-1}$, instead of $219 \mathrm{~kg} \mathrm{~m}^{-3}$ for the one obtained at $900 \mathrm{~K} \mathrm{~min}^{-1}$ (cf. Table 2 and Fig. 2). High HR lead to low density charcoals, as it was observed by previous authors [9-12]. The ratio of apparent densities is here as high as 2.3 .

Volatile matter (VM) yield during pyrolysis has been calculated for the $3 \mathrm{HR}$ conditions and compared with standard tests (cf. Table 1). Briefly, a standard test consists of putting rapidly between 1 and $2 \mathrm{~g}$ of wood in a $1223 \mathrm{~K}$ furnace for a duration of $1 \mathrm{~h}$. The influence of the HR during pyrolysis on the $\mathrm{VM}$ yield is shown in Fig. 2. It can be seen that if a log scale is adopted for the HR axis, the charcoal particle apparent density has an almost linear evolution. This result can have practical applications.

The present results can also be expressed in terms of the porosity of the particles. The density of the solid phase

Table 2

Properties of the initial wood and of the charcoals obtained by pyrolysis at 2.6 , 12 and $900 \mathrm{~K} \mathrm{~min}^{-1}$

\begin{tabular}{llllc}
\hline Heating rate $\left(\mathrm{K} \mathrm{min}^{-1}\right)$ & & 2.6 & 12 & 900 \\
\hline Initial beech wood & & & & \\
Diameter of a particle & $\mathrm{mm}$ & 10.20 & 10.20 & 10.21 \\
Weight of a particle (dry basis) & $\mathrm{g}$ & 0.3752 & 0.3699 & 0.3761 \\
Apparent density (dry basis) & $\mathrm{kg} \mathrm{m}^{-3}$ & 664 & 666 & 675 \\
Charcoals & & & & \\
Equivalent diameter of a particle & $\mathrm{mm}$ & 6.99 & 6.92 & 7.76 \\
Weight of a particle & $\mathrm{g}$ & 0.0912 & 0.0714 & 0.0535 \\
Apparent density & $\mathrm{kg} \mathrm{m}^{-3}$ & 511 & 449 & 219 \\
Porosity & $\%$ & 70 & 74 & 87 \\
VM yield & $\mathrm{wt} \%$ & 68 & 73 & 78 \\
\hline
\end{tabular}

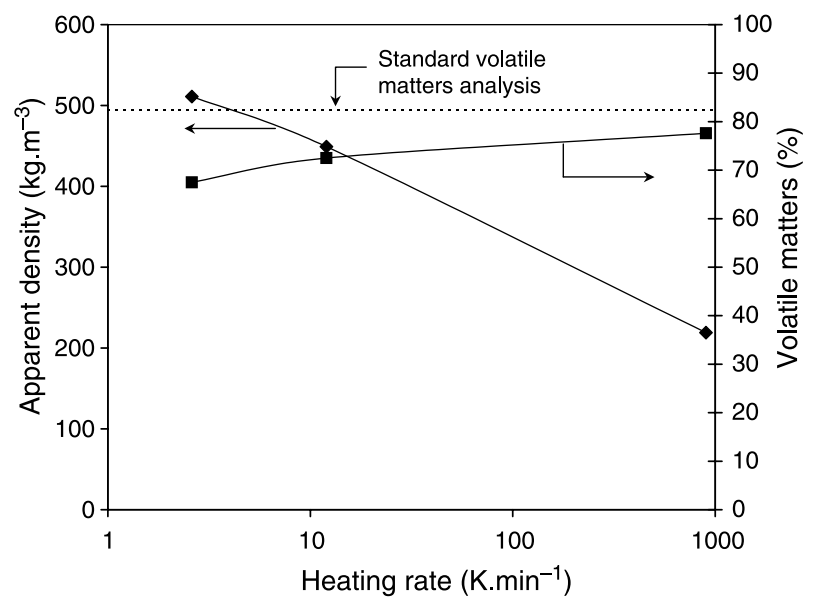

Fig. 2. Volatile matter yield ( $\square$ ) and apparent density ( $\bullet$ ) of the charcoals prepared at three different heating rates.

$\rho_{\text {solid }}$ - carbon and ash-was measured using helium pycnometry for the three charcoals obtained at different HR. A similar value of $1700 \mathrm{~kg} \mathrm{~m}^{-3}$ has been found. This enables calculation of the porosity of the particles as indicated in Table 2:

$\varepsilon=1-\frac{\rho_{\text {apparent }}}{\rho_{\text {solid }}}$

The porosity of the charcoals lie from 70 to $87 \%$ for the charcoals prepared at 2.6 and $900 \mathrm{~K} \mathrm{~min}^{-1}$, respectively.

The total pore surface area of the three samples were measured using both $\mathrm{N}_{2}$ and Ar adsorption/desorption analysis. Mercury porosimetry was used to determine the pore size distribution above $3 \mathrm{~nm}$.

\subsection{1. $\mathrm{N}_{2}$ or Ar adsorption/desorption analysis}

The pore size distribution of micropores $(<2 \mathrm{~nm})$ and mesopores (between 2 and $50 \mathrm{~nm}$ ) were characterised using $\mathrm{N}_{2}$ as the adsorbed gas, on an ASAP 2010 apparatus. Many authors $[13,14]$ stated that diffusion of $\mathrm{N}_{2}$ in micropores is very slow and equilibrium is difficult to reach, explaining the problems encountered to measure surface areas in microporous samples with $\mathrm{N}_{2}$ as adsorptive. $\mathrm{CO}_{2}$ or Ar are generally preferred to $\mathrm{N}_{2}$ in the case of microporous structures: analysis was also carried out using Ar. The total pore surface area of the charcoal particles was then calculated from these standard tests by the Langmuir method, classically used for microporous samples. The values are reported in Table 3.

For both $\mathrm{N}_{2}$ and Ar analysis, isotherm curves for low and medium HR charcoals are comparable. As a result, Langmuir surface area values are very close: $637 \mathrm{~m}^{2} \mathrm{~g}^{-1}$ ( $\mathrm{N}_{2}$ analysis) and $617 \mathrm{~m}^{2} \mathrm{~g}^{-1}$ (Ar analysis) for low $\mathrm{HR}$ charcoal, and $605 \mathrm{~m}^{2} \mathrm{~g}^{-1}\left(\mathrm{~N}_{2}\right.$ analysis) and $620 \mathrm{~m}^{2} \mathrm{~g}^{-1}$ (Ar analysis) for medium HR charcoal. The isotherm shape for $\mathrm{Ar}$ analysis reveals a totally microporous surface for the two samples whereas analysis with $\mathrm{N}_{2}$ exhibits a low mesoporosity, calculated by BJH method applied on the desorption curves, at 73 and $72 \mathrm{~m}^{2} \mathrm{~g}^{-1}$ for the low and medium HR respectively. 
Table 3

Surface area of the three charcoals measured by adsorption/desorption technique with $\mathrm{N}_{2}$ and Ar on an ASAP 2010 apparatus

\begin{tabular}{llll}
\hline Sample & $\operatorname{Ar}\left(\mathrm{m}^{2} \mathrm{~g}^{-1}\right)$ & $\mathrm{N}_{2}\left(\mathrm{~m}^{2} \mathrm{~g}^{-1}\right)$ & \\
\cline { 2 - 4 } & Langmuir & Langmuir & $\begin{array}{l}\mathrm{BJH} \\
\text { (mesopores) }\end{array}$ \\
\hline Low HR (2.6 K min & & 73 \\
medium HR $\left(12 \mathrm{~K} \mathrm{~min}^{-1}\right)$ & 617 & 637 & 72 \\
\hline
\end{tabular}

For charcoal prepared at the $\mathrm{HR}$ of $900 \mathrm{Kmin}^{-1}, \mathrm{~N}_{2}$ adsorption/desorption tests results were not repeatable, and could vary between 22 and $64 \mathrm{~m}^{2} \mathrm{~g}^{-1}$. Test duration was very long because equilibrium could not be reached. Ar analysis was then performed several times, but the same problem was encountered. It is commonly observed that biomass charcoals, unlike coals, are very difficult to analyse using the adsorption/desorption technique.

\subsubsection{Mercury porosimetry analysis}

Mercury porosimetry technique enables us to quantify the volume and then to calculate the surface area of the pores from macroscopic size down to $3 \mathrm{~nm}$, by injecting mercury into the charcoal under increasing pressure, from 0 to 4000 bar. The cumulative pore volume of three charcoals were measured using AUTOPORE II 9220 apparatus; the test was repeated for the two samples prepared under two extreme conditions, i.e. 2.6 and $900 \mathrm{~K} \mathrm{~min}^{-1}$ (cf. Fig. 3). The corresponding surface area distribution can be calculated from the pore volume data. The surface area of the pores larger than $3 \mathrm{~nm}$ were determined from these data, and reported in Table 4.

As indicated by the plots in Fig. 4, the surface area of the pores larger than $100 \mathrm{~nm}$ is very small. It is important to note that in all experiments it was observed that when decreasing the pressure, mercury was not extruded from the sample as it should be in a dedicated experiment. The most likely explanation put forward by previous authors [16] is that the charcoal structure was broken during the increase of pressure

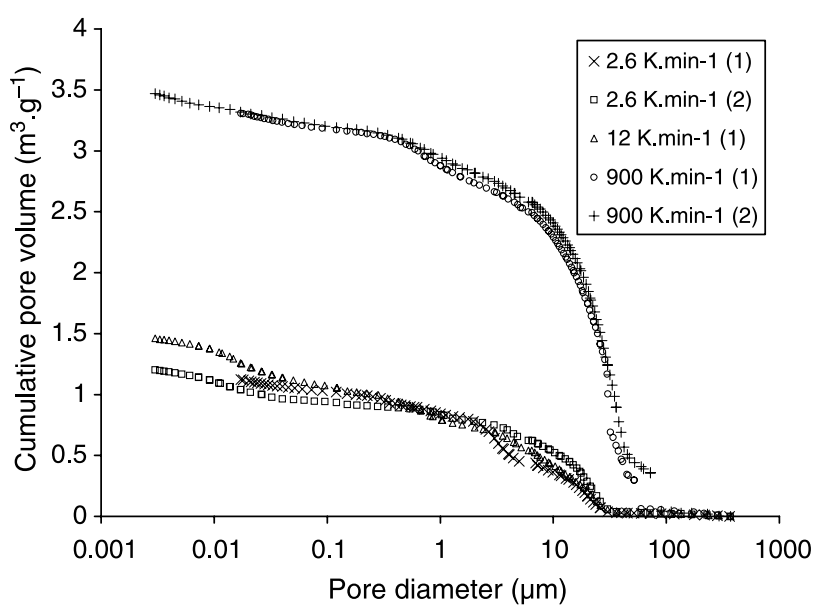

Fig. 3. Cumulative pore volume versus pore diameter resulting from mercury porosimetry analysis for the three charcoals.
Table 4

Porosity, pore volume and surface area of three charcoals measured by mercury porosimetry on an AUTOPORE II 9220 apparatus

\begin{tabular}{lllll}
\hline Sample & $\begin{array}{l}\text { Calculated } \\
\text { porosity } \\
(\%)\end{array}$ & $\begin{array}{l}\text { Measured } \\
\text { porosity } \\
(\%)\end{array}$ & $\begin{array}{l}\text { Pore } \\
\text { volume } \\
\left(\mathrm{ml} \mathrm{g}^{-1}\right)\end{array}$ & $\begin{array}{l}\text { Pore surface } \\
\text { area } \\
\left(\mathrm{m}^{2} \mathrm{~g}^{-1}\right)\end{array}$ \\
\hline $\begin{array}{l}\text { Low HR } \\
\left(2.6 \mathrm{~K} \mathrm{~min}^{-1}\right)\end{array}$ & 70 & 65 & 1.203 & 106 \\
$\begin{array}{l}\text { Medium HR } \\
\left(12 \mathrm{~K} \mathrm{~min}^{-1}\right)\end{array}$ & 74 & 71 & 1.460 & 127 \\
$\begin{array}{l}\text { High HR } \\
\left(900 \mathrm{~K} \mathrm{~min}^{-1}\right)\end{array}$ & 87 & 85 & 3.470 & 120 \\
\hline
\end{tabular}

and mercury was not extruded during the pressure decrease. Therefore, the values reported here are probably affected by a large degree of uncertainty, despite the good repeatability of the measures.

The porosities measured by mercury porosimetry-that exclude the pores smaller than $3 \mathrm{~nm}$-confirm the values calculated from the apparent densities of charcoals (cf. Table 4): the first are approximately $3 \%$ smaller than the last.

\subsubsection{Scanning electron microscopy (SEM)}

An attempt was made to observe differences in the structure of different charcoals, as did several authors [11,13,16,22] using SEM. Our SEM observations-an example is given in Fig. 5-revealed a very non-uniform structure, making it very difficult to compare different charcoals, and even different zones inside the same charcoal particle. Moreover, using the SEM technique, it was not possible to observe the actual reactive surface, i.e. at nanometer scale. As a consequence, even qualitative analysis was difficult using SEM.

\section{Gasification of the charcoals}

\subsection{Experimental set-up}

The charcoals obtained at three different HR were gasified by steam in a single particle situation, using a specially

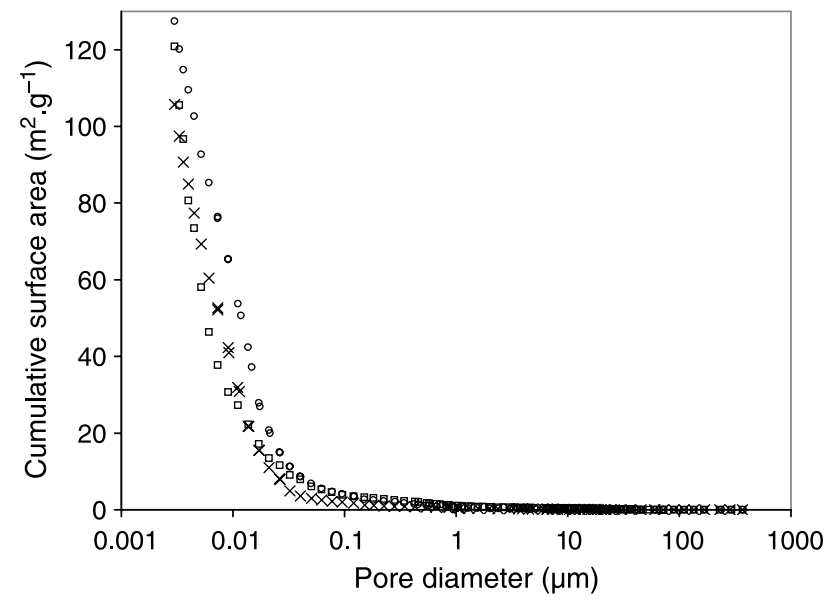

Fig. 4. Cumulative pore surface area versus pore diameter resulting from mercury porosimetry analysis for the charcoals prepared at $2.6(\times), 12(\bigcirc)$ and $900(\square) \mathrm{K} \mathrm{min}^{-1}$. 


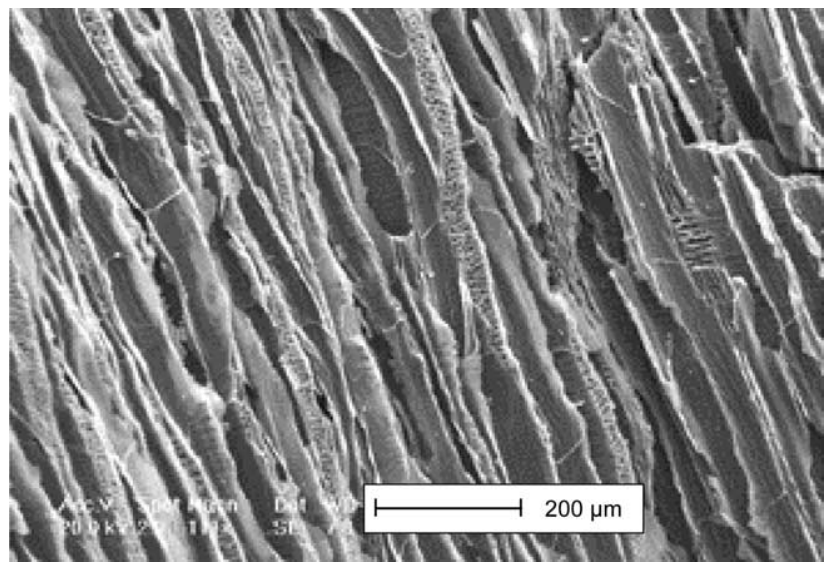

Fig. 5. SEM picture of the initial char.

designed macro-TG reactor. The general principle consists of holding the particle inside a reactor swept by the oxidising agent $\mathrm{H}_{2} \mathrm{O}$ in a $\mathrm{N}_{2}$ atmosphere gas, at a controlled temperature and at atmospheric pressure. The weight of the sample is continuously monitored in order to observe the conversion of the charcoal. The experimental set-up is presented in Fig. 1. The reactor is a $2 \mathrm{~m}$ long quartz reactor heated electrically (1). The atmosphere is generated by a $\mathrm{N}_{2}$ flow controlled by a mass flowmeter/controller (M) and a liquid water flow controlled by a rotameter (7) and directed to a steam generator (5), whose output temperature is controlled at $473 \mathrm{~K}$. The gas mixture is then fed to two coiled tubes (4) placed inside the reactor to preheat the atmosphere gas. The gas flow rate was high enough so that no limitations by external mass $\left(\mathrm{H}_{2} \mathrm{O}\right)$ transfer occurred. This was tested by varying the gas flow rate: this had no impact on the gasification rate. The precision load cell (10) holds a nickel hanging wire and basket (9) in which particles are placed.

One difficulty encountered when constructing the macro-TG was to control the gas flow through the holding wire aperture at the top of the reactor. Indeed, steam should not escape from the reactor, to be sure of the molar fraction of $\mathrm{H}_{2} \mathrm{O}$ in the reactor atmosphere gas and to prevent water condensation. Neither should air enter the reactor, to avoid a reaction between carbon and oxygen. A $4 \mathrm{~N} \mathrm{~L} \mathrm{~min}^{-1}$ flow of $\mathrm{N}_{2}$ was then fed through a small tube (8) to the vertical tube surrounding the hanging wire in order to create a counter flow. The flow rate of this additional $\mathrm{N}_{2}$ actually entering the reactor was measured accurately by the tracer gas method at $0.91 \mathrm{~L} \mathrm{~min}^{-1} \mathrm{STP}$ and taken into account in the composition of the atmosphere gas.

\subsection{Experimental procedure}

The reactor was first heated under $\mathrm{N}_{2}$ atmosphere at the operating temperature, $1200 \mathrm{~K}$, until a stable regime was achieved. The basket was then lifted from the bottom of the reactor, and hung on the load cell. A constant mass achieved under $\mathrm{N}_{2}$ ensured that adsorbed gas at the surface of the charcoal $\left(\mathrm{H}_{2} \mathrm{O}\right.$, hydrocarbons) was released before operating the gasification by $\mathrm{H}_{2} \mathrm{O}$. The water flow was then established, producing an atmosphere of $20 \%$ mole fraction of $\mathrm{H}_{2} \mathrm{O}$ in $\mathrm{N}_{2}$.
The mass of the sample progressively decreased until a constant mass - that of ashes-was achieved to conclude a test.

The experiments were made with seven particles together. Using several particles rather than a single one presented two advantages: (i) it enabled results to be obtained from an average of seven particles. Indeed, it is known that disparities between different biomass particles exist; (ii) it increased the signal/noise ratio of the load cell by increasing the total mass of the sample: the weight of a single charcoal particle was very small $(<100 \mathrm{mg})$. The seven particles were placed in a horizontal plane and were not in contact together, so that no interaction between particles occurred.

\section{Results and discussion}

The conversion $X$ during steam gasification was calculated following Eq. (2). The evolution of $X$ versus time for all the experiments is plotted in Fig. 6

$X=\frac{m_{\text {init }}-m}{m_{\text {init }}-m_{\text {ash }}}$

The repeatability of the experiments was checked by repeating each test several times: 6,2 and 3 times for the charcoals prepared at $2.6,12$ and $900 \mathrm{~K} \mathrm{~min}^{-1}$ respectively. The results in Fig. 6 show that a good repeatability was achieved, considering that biomass is used here and that the size of the particles is important. Some dispersion still existsa deviation of about $10 \%$ for six tests is observed-showing that repeating all experiments is necessary.

The examination of the results first indicates that the general shape of the conversion curves versus time is globally almost linear. Previous authors [5,12,15,19] also observed a similar pattern, but with $\mathrm{CO}_{2}$ as the oxidant.

The results indicate clear differences in the reaction rates for the three charcoals. The linear shape of the curves enables us to extrapolate the curves to $X=1$ in order to determine a time for complete gasification, as shown in Fig. 6. The times observed for complete gasification are $1880 \mathrm{~s}$ (31 min $20 \mathrm{~s}), 1320 \mathrm{~s}$

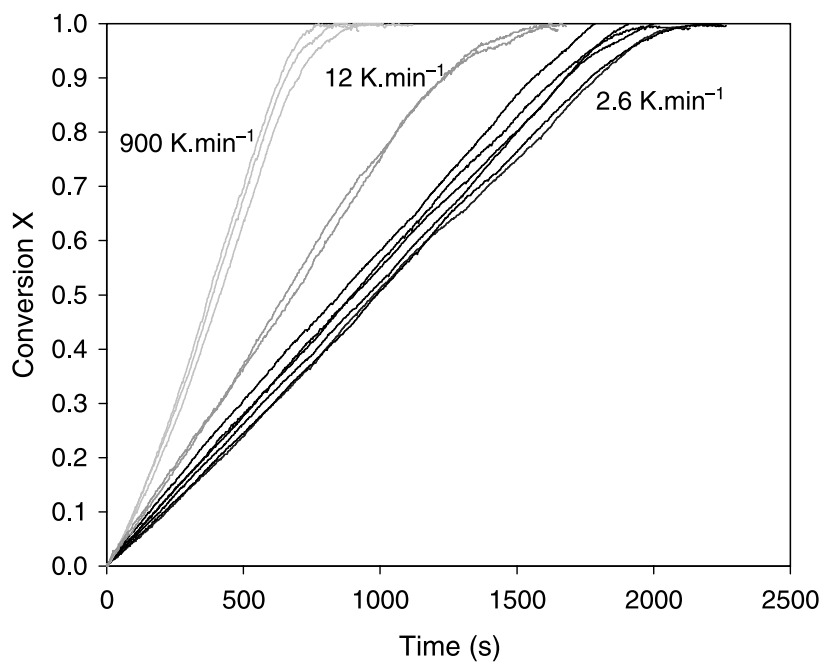

Fig. 6. Gasification progress under $20 \% \mathrm{H}_{2} \mathrm{O}$ at $1200 \mathrm{~K}$ of charcoal particles pyrolysed at $2.6,12$ and $900 \mathrm{~K} \mathrm{~min}^{-1}$. 
(22 $\mathrm{min})$, and $720 \mathrm{~s}$ (12 $\mathrm{min}$ ) for the charcoals prepared at 2.6, 12 and $900 \mathrm{~K} \mathrm{~min}^{-1}$ respectively. Such differences are significant if one considers an industrial process. They indicate that depending on the pyrolysis process used upstream of the gasifier, the gasification duration can vary in a ratio of 1-2.6 for similar operating gasification conditions. As a reference, and regarding classical values for the activation energy of the charcoal gasification by $\mathrm{H}_{2} \mathrm{O}$ reaction, the gasification temperature should be increased by almost $100 \mathrm{~K}$ to gasify the charcoal prepared at $2.6 \mathrm{~K} \mathrm{~min}^{-1}$ in the same duration as the charcoal prepared at $900 \mathrm{~K} \mathrm{~min}^{-1}$. In the following sections we try to provide explanations for such differences in the behaviour of the different charcoals during gasification.

The differences in the gasification rates observed here may be due to limitations of the reaction by heat or mass transfer inside the particles. In order to eliminate this possibility, additional experiments were carried out using smaller particles, obtained from char spheres broken into four or five pieces. In the case of char pyrolysed at the higher HR, i.e. with the lower apparent density $-219 \mathrm{~kg} \mathrm{~m}^{-3}$, no difference in gasification rate could be observed between broken and entire particles, indicating that no internal transfers limitation occur. In the case of char pyrolysed at the lower HR, i.e. with the higher apparent density, $511 \mathrm{~kg} \mathrm{~m}^{-3}$, the broken particles exhibit a time for complete conversion that is $10 \%$ lower than the entire particles, showing that the gasification is only slightly limited by internal transfers. A previous modelling study [23] leads to the same conclusion. However, this limitation is not significant enough to explain the large difference in gasification times of chars obtained at low and high HR.

The explanation has to be found in the characteristics of the chars prepared at three different HR.

A first explanation for the high reactivity of the high HR charcoal could be that it did not suffer from thermal annealing, or thermal deactivation, during the pyrolysis stage. Indeed, the soaking time under $\mathrm{N}_{2}$ at the final temperature of $1200 \mathrm{~K}$ was much smaller than in the case of two other charcoals: 8 min instead of $1 \mathrm{~h}$. In order to clarify this point, specific experiments were carried out at high HR but this time with a soaking time of $1 \mathrm{~h}$. No difference in gasification rate was observed between the high HR charcoals with soaking times of 8 min or $1 \mathrm{~h}$. It can be concluded that the beech charcoal does not undergo thermal annealing at a temperature of $1200 \mathrm{~K}$ in a duration of $1 \mathrm{~h}$.

In the following sections, the experimental results are confronted to different kinetic models in order to explain the differences in reactivity of the three charcoals.

\subsection{Homogeneous model}

The most classical model for dealing with the reaction of a porous carbonaceous medium with an oxidant gas is the so called homogeneous model

$\frac{\mathrm{d} m}{\mathrm{~d} t}=-k_{\mathrm{app}} m$ in which the apparent kinetics constant $k_{\text {app }}\left(\mathrm{s}^{-1}\right)$, currently called apparent reactivity, is a function of temperature and concentration in the gas phase of the species involved in the reactions. Different expressions for $k$ can be found in the literature [24-26]. These expressions were developed to describe both the increase of gasification rate with an increase of the oxidant gas concentration-here $\mathrm{H}_{2} \mathrm{O}$ - and the inhibition of the gasification process by $\mathrm{H}_{2}$ produced by the reaction. This expression can be used if no limitation by heat/ mass transfers inside the particle occurs. Since in our experiments the temperature and the water vapour content were similar throughout the whole gasification process, the apparent reactivity should be a constant for all experiments. The plots in Fig. 7 clearly indicate that it is not the case here. From the beginning of the experiments, clear differences appear between the apparent reactivities of the different charcoals. When the gasification reaction progresses, a very important increase in the apparent reactivity is observed, leading to values $10-20$ times higher than at the beginning of the experiments. The homogeneous model is therefore not suitable for describing the situation.

\subsection{Surface related model}

Differences in the reactive surface can be an explanation for the differences in the apparent reactivities of the three charcoals, as suggested by numerous authors [7,13,16,18,27-29].

It is admitted today that in heterogeneous reactions such as $\mathrm{C}-\mathrm{H}_{2} \mathrm{O}, \mathrm{C}-\mathrm{CO}_{2}$, or $\mathrm{C}-\mathrm{O}_{2}$, the apparent reactivity is highly influenced by the reactive surface. As a consequence, Eq. (3) can be expressed as

$\frac{\mathrm{d} m}{\mathrm{~d} t}=-k s_{\mathrm{int}} S_{\mathrm{r}} m$

where $k s_{\text {int }}\left(\mathrm{g} \mathrm{s}^{-1} \mathrm{~m}^{-2}\right)$ is the intrinsic reactivity that should be constant since all experiments were carried out in the same conditions. The determination of the reactive surface $S_{\mathrm{r}}$ $\left(\mathrm{m}^{2} \mathrm{~g}^{-1}\right)$ is a subject for discussion. Beyond the fact that the initial value measurement is still questionable as presented before, its evolution along the gasification process remains

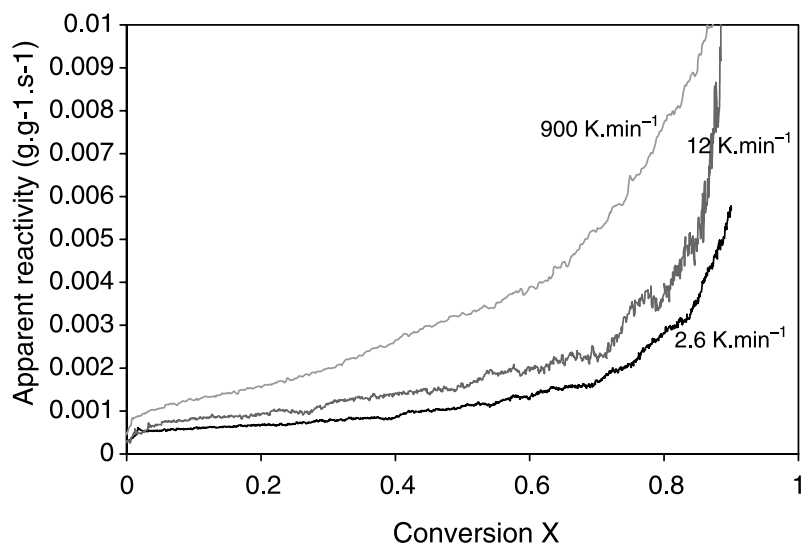

Fig. 7. Apparent reactivity versus conversion of the three charcoals prepared at $2.6,12$ and $900 \mathrm{~K} \mathrm{~min}^{-1}$ during steam gasification under $20 \% \mathrm{H}_{2} \mathrm{O}$ at $1200 \mathrm{~K}$. 
difficult to describe, and makes modelling of gasification by $\mathrm{H}_{2} \mathrm{O}$ very complex. Several works $[13,16,18,22,27]$ have dealt with the increase of char reactivity during conversion. It seems to develop with an increase of the reactive surface area. They stated that the reaction opens up the pore volume by enlarging the connections between the pores. The surface area available for reaction is then increased by making new pores accessible to the reactants. Moreover, numerous authors have pointed out that fracturation of the particle occurred during the process, creating additional reactive surface together with facilitating the diffusion of the reactant and product gases inside the core of the particles. This phenomenon has been observed in our experiments as illustrated in Fig. 8, where fracturation clearly appears after only $20 \%$ of conversion.

The estimation of the charcoal pore surface area that actually participates in heterogeneous carbon reactions was extensively discussed in various research works $[14,16,28,30,31]$ in the case of the reactions of oxidation by $\mathrm{O}_{2}$, gasification by $\mathrm{H}_{2} \mathrm{O}$ or $\mathrm{CO}_{2}$ and the reduction of $\mathrm{NO}$ at the surface of a porous carbon. They came to the conclusion that the micropores $(<2 \mathrm{~nm})$ probably do not participate in the reaction, and that the surface developed by the macropores and the mesopores only is a better indicator for the reactive surface than the total pore surface area measured by adsorption/ desorption, in which the contribution of the micropore surface area is important. This is investigated below.

\subsubsection{Beginning of the gasification reaction}

In a first approach, we will refer to the very beginning of the gasification experiments, i.e. at $X=0.05$, when the gasification reaction has just started, but the particles are not fractured. At this time, the reactive surfaces are known from the measurements on the initial charcoals.

The total pore surface area is classically used as a reference reactive surface. From (3) and (4), apparent reactivity can be written:

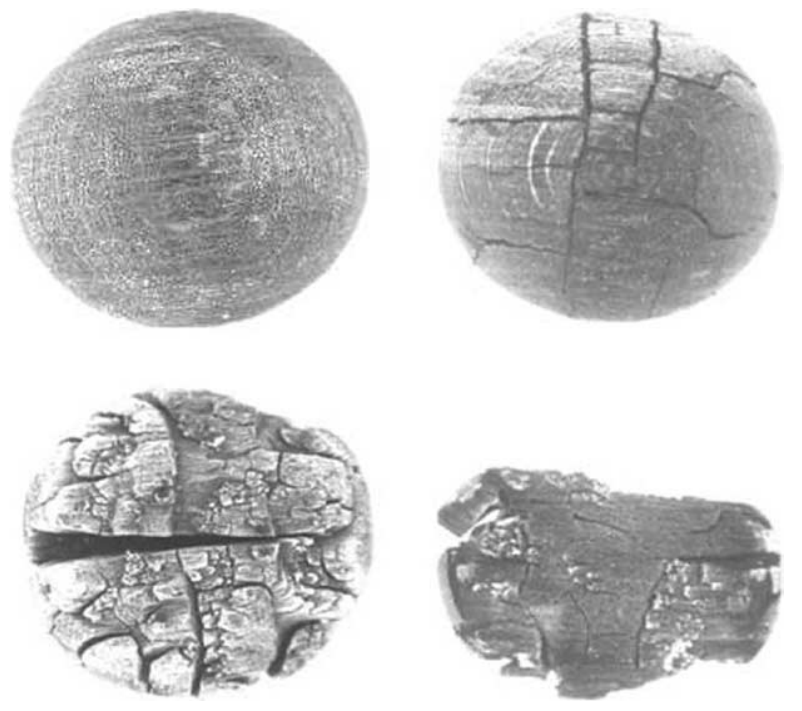

Fig. 8. Macroscopic evolution of a gasifying particle (0, 20, 50, 70\% conversion) $k_{\text {app }}=k s_{\text {int }} S_{\text {r }}$

If the total surface area is a good indicator for the reactive surface, then $k_{\text {app }}$ should be proportional to this surface. The plot of the total pore surface area measured by $\mathrm{N}_{2}$ adsorption/desorption versus the initial apparent reactivity of the charcoals (at $X=0.05$ ), shown in Fig. 9, does not indicate a correlation with the expected positive evolution. The total pore surface area is therefore not a good indicator for the reactive surface.

We plotted in Fig. 9 the evolution of the surface area of pores larger than $3 \mathrm{~nm}$, measured by $\mathrm{Hg}$ intrusion. Their evolution with the initial apparent reactivity of the charcoals is closer to a linear shape. The mesopore and macropore surface area seems to be a better indicator for the reactive surface than the total surface area, but is not sufficient to predict the charcoal reactivity.

\subsubsection{Progress of the reaction}

When the gasification reaction progresses, very important increases in the reactivities are observed, leading to values as high as $10-20$ times greater than at the beginning. If the total pore surface area was representative of the reactive surface $S_{\mathrm{r}}$, according to Eq. (5), an increase in the same proportion of the total pore surface area along the gasification reaction could be an explanation. But results from the literature [13,16,18,22,27] do not indicate such high increases in the char reactive surface during the gasification process: this tends to show again that this surface is not the best parameter for explaining the evolution of charcoal gasification reactivity.

\subsection{Ash related model}

The catalytic effect of the ashes in the gasification of coals has been widely studied in the literature [32-35], as coals present very high ash content compared to biomass chars.

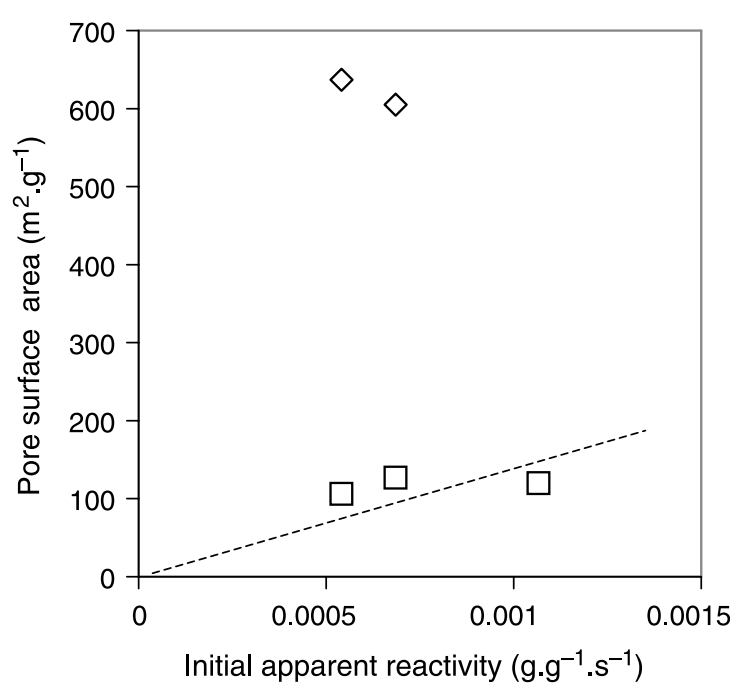

Fig. 9. Total pore surface area $(\diamond)$ and surface area of the pores larger than $3 \mathrm{~nm}(\square)$ versus the apparent reactivity of the three charcoals at $X=0.05$. 
However, previous authors focused on the role of ashes in the gasification of biomass chars [20,36]. In order to investigate this point, results will be confronted to a model of the following type

$\frac{\mathrm{d} m}{\mathrm{~d} t}=-k a_{\mathrm{int}}[\mathrm{Ash}] m$

where [Ash] is the ash mass fraction in the carbon matrix, and $k a_{\text {int }}\left(\mathrm{g}_{\text {char }} \mathrm{g}_{\text {ash }}^{-1} \mathrm{~s}^{-1}\right)$ is the intrinsic reactivity related to the ash fraction. Eq. (3) and (6) lead to:

$k_{\text {app }}=k a_{\text {int }}[$ Ash $]$

\subsubsection{Beginning of the gasification reaction}

If the model in Eq. (6) is adapted, then a linear correlation between the apparent reactivities and the ash fraction in the charcoals should be observed. We plotted in Fig. 10 the values of $k_{\text {app }}$ of three charcoals at the beginning of the reaction versus their content in ash. The plot indicates a clear linear increase.

\subsubsection{Progress of the reaction}

We have plotted in Fig. 11 the evolution of $k a_{\text {int }}$ along the gasification process. If this model was an exact representation of the gasification process, the $k a_{\text {int }}$ values should be constant along the process and similar for the three charcoals. One can notice that they are not equal, but they appear not to change in a large range along the gasification process: the ratio between the higher and the smaller values for three charcoals is less than two instead of 10-20 when using the homogeneous model.

This model is much more accurate than the homogeneous model for describing the gasification reaction. Summarising these results it can be thought that the ash percentage has an effect on the gasification reaction. This hypothesis is supported by the ash content of the initial beech wood, reported in Table 5. The analysis, performed by Inductive Coupling Plasma (ICP), reveals a great quantity of calcium and potassium in the ash (45.5 and 38\% of the total mass of ash respectively). Calcium and potassium are known to have a

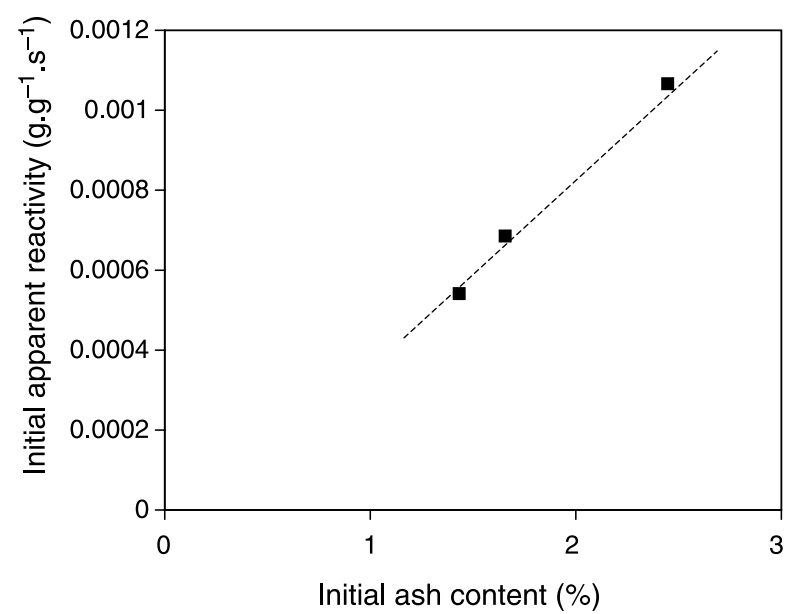

Fig. 10. Apparent reactivity at $X=0.05$ versus ash content of the three charcoals.

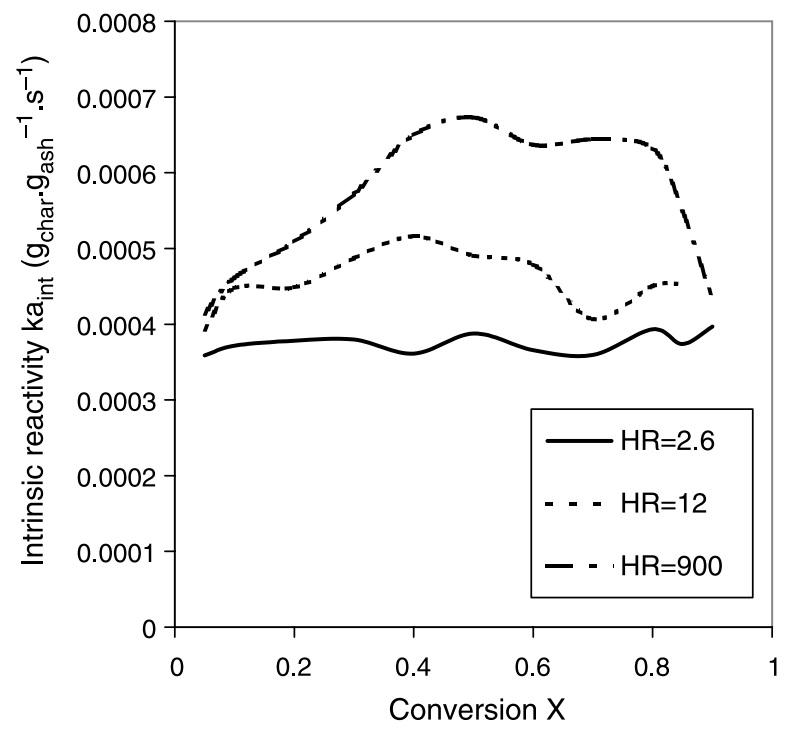

Fig. 11. Evolution of the intrinsic reactivity related to ash fraction along the gasification reaction of the three charcoals.

catalytic effect on the gasification of chars and coals $[20,32,33]$.

Nevertheless, the effect of ash alone is not sufficient to explain the reactivity of the different charcoals to water vapour. It is probable that the gasification reaction is both influenced by the reactive surface, which is not easy to identify, and by the amount of ash. At this stage, it was not possible to distinguish the two effects. Indeed, regarding the difficulties encountered in measuring reactive surfaces as discussed before, measurements of reactive surfaces along the reaction were not undertaken.

\section{Conclusion}

Changing the heating rate during the pyrolysis of a $1 \mathrm{~cm}$ characteristic size beech wood particle from very low$2.6 \mathrm{~K} \mathrm{~min}^{-1}$ — to very high_ $900 \mathrm{~K} \mathrm{~min}^{-1}$-yields charcoals with drastically different properties. At the lower heating rate, the charcoal is as dense as $511 \mathrm{~kg} \mathrm{~m}^{-3}$ and its total pore surface area is as high as $637 \mathrm{~m}^{2} \mathrm{~g}^{-1}$, while at the higher heating rate, the charcoal density is $219 \mathrm{~kg} \mathrm{~m}^{-3}$ only. The apparent density follows a linear evolution versus the log of the heating rate. The volume reduction from the initial $10.2 \mathrm{~mm}$ diameter wood spherical particles to the ovoid charcoal

Table 5

Ash content of the initial beech wood

\begin{tabular}{lll}
\hline & $10^{-3}$ wt\% in the wood & wt\% in the ash \\
\hline $\mathrm{Ca}$ & 97 & 45.5 \\
$\mathrm{~K}$ & 81 & 38.0 \\
$\mathrm{Mg}$ & 19 & 8.9 \\
$\mathrm{P}$ & 6.1 & 2.9 \\
$\mathrm{Mn}$ & 4.95 & 2.3 \\
$\mathrm{Na}$ & 3.11 & 1.5 \\
$\mathrm{Fe}$ & 1.64 & 0.8 \\
$\mathrm{Zn}$ & 0.37 & 0.2 \\
$\mathrm{Cu}$ & 0.21 & 0.1 \\
\hline
\end{tabular}


particles is nevertheless similar in the three cases of heating rate, with a ratio of approximately three between the volume of the wood particles and the volume of the charcoal particles. The difference in apparent densities is therefore due to the differences in the volatile matter yield.

A new macro-TG experiment was developed, and used to submit the charcoal particles to gasification under $20 \% \mathrm{H}_{2} \mathrm{O}$ in $\mathrm{N}_{2}$ at a temperature of $1200 \mathrm{~K}$. A good repeatability in the experiments was achieved; we demonstrate that repeating all experiments is nevertheless necessary. The charcoal obtained at different heating rates exhibit very different gasification kinetics. The gasification rate of the charcoal with a high density - i.e. prepared at a low heating rate-is 2.6 times lower than that of the low density charcoal-i.e. prepared at a high heating rate. Such differences have a strong impact on the design of an industrial process. The results of this work are likely to be useful for the optimisation of industrial staged gasifiers.

This work also demonstrates that the lower reactivity of the charcoal produced under low or medium HR is not due to thermal deactivation during pyrolysis: maintaining a charcoal obtained at a high heating rate for $1 \mathrm{~h}$ at $1200 \mathrm{~K}$ does not reduce its reactivity towards $\mathrm{H}_{2} \mathrm{O}$.

An attempt was made to find a correlation between a reactive surface and the reactivity of the charcoals during gasification by $\mathrm{H}_{2} \mathrm{O}$. The total pore surface, whatever measured by $\mathrm{N}_{2}$ or $\mathrm{Ar}$ adsorption, is not a good indicator for the reactive surface. This can be explained by the fact demonstrated by previous authors that micropores-which do not actively participate to the gasification reactionrepresent an important part of the total surface area. The mesopore plus macropore surface area seems to be a better indicator for the reactive surface during gasification, but cannot be precisely correlated to the reactivity of the charcoals.

The present results indicate that the amount of ash in the charcoals probably plays an important role in the gasification process. Indeed, the initial apparent reactivities of the charcoals are proportional to the initial ash content of the charcoals. Moreover, throughout the gasification process, the reactivity of the charcoals related to their ash content appears to change by a ratio of 2 only, whereas neglecting this effect-considering an homogeneous model-leads to ratios of 10-20. It is probable that both reactive surface evolution and ash content evolution play a role in the gasification by $\mathrm{H}_{2} \mathrm{O}$. It was not possible in this work to differentiate between the two effects.

\section{Acknowledgements}

The research is partly funded by the European Commission in the framework of 5th Programme, Lift off project, contract NNE5/2001/704.

\section{References}

[1] Van den Aarsen FG, Beenackers AACM, Van Swaaij WPM. Wood pyrolysis and carbon dioxide char gasification kinetics in a fluidized bed. In: Overend R, Milne T, Mudge L, editors. Fundamentals of thermochemical biomass conversion. New York: Elsevier; 1985. p. 691-715.

[2] Rensfelt E, Blomkvist G, Ekstrom C, Engstrom S, Espents BG, Linnanki L. Basic gasification studies for development of biomass medium-btu gasification processes. IGT symposium; 1978.

[3] Harris DJ, Smith IW. Proc Combust Sci 1990;23:1185-90.

[4] Walker PLJ, Rusinko FJ, Austin LG. Advances in catalysis, vol. 11. New York and London; 1959. p. 133-221.

[5] Kumar M, Gupta RC. Fuel 1994;73:1922-5.

[6] Walker PLJ. Char properties and gasification. In: Overend R, Milne T, Mudge L, editors. Fundamentals of thermochemical biomass conversion. New York: Elsevier; 1985. p. 485-509.

[7] Roberts DG, Harris DJ, Wall TF. Energy Fuels 2003;17:887-95.

[8] Van de steene L, Salvador S, Napoli A. Rice husk, straw and bark behaviour during combustion, pyrolysis and gasification: fundamental study. 12th European conference and technology exhibition on biomass for energy, industry and climate protection, June 17-21, 2002. The Netherlands: Amsterdam RAI International; 2002.

[9] Zanzi R, Sjostrom K, Bjornbom E. Fuel 1996;75:545-50.

[10] Therssen E, Gourichon L, Delfosse L. Combust Flame 1995;103:115-28.

[11] Fushimi C, Araki K, Yamaguchi Y, Tsutsumi A. Ind Eng Chem Res 2003; 42:3922-8.

[12] Chen G, Sjostrom K, Bjornbom E. Ind Eng Chem Res 1992;31:2764-8.

[13] Cetin E, Moghtaderi B, Gupta R, Wall TF. Fuel 2004;83:2139-50.

[14] Aarna I, Suuberg EM. Changes in reactive surface area and porosity during char oxidation. 27th International symposium on combustion, Philadelphia; 1998. p. 2933-9.

[15] Dasappa S, Paul PJ, Mukunda HS, Shrinivasa U. Chem Eng Sci 1994;49: 223-32.

[16] Dutta S, Wen CY, Belt RJ. Ind Eng Chem 1977.

[17] Klose W, Wolki M. Fuel 2005;84:885-92.

[18] Salatino P, Senneca O, Masi S. Carbon 1998;36:443-52.

[19] Standish N, Tanjung AFA. Fuel 1988;67:666-72.

[20] Encinar JM, Gonzalez JF, Rodriguez JJ, Ramiro MJ. Fuel 2001;80: 2025-36.

[21] Van de steene L, Salvador S, Charnay G. Combust Sci Technol 2000;159: 255-79.

[22] Manocha S, Chauhan V, Manocha L. Carbon Sci 2002;3:133-41.

[23] Golfier F, Mermoud F, Salvador S, Dirion JL, Van de Steene L. Modeling of char gasification at particle scale: how to select the best assumptions in the scope of fixed bed modeling. Second world conference and technology exhibition on biomass for energy, industry and climate protection, Rome, Italy, May 10-14, 2004.

[24] Chornet E, Baldoroso JM, Tarki HT. Fuel 1979;58:395.

[25] Blackwood JD, McGrory F. Aust J Chem 1958;11:16-23.

[26] Gadsby J, Hinshelwood CN, Sykes KW. Proc R Soc Lond Ser A $1946 ; 129$.

[27] Walker PR, Foresti RJJ, Wright CC. Ind Eng Chem 1953;45:1703-10.

[28] Radovic LR, Walker PLJ, Jenkins RG. Fuel 1983;62:849-56.

[29] Klose W, Wolki M. Fuel, Corrected proof, in press

[30] Commandre JM, Stanmore BR, Salvador S. Combust Flame 2002;128: 211-6.

[31] Salvador S, Commandre JM, Stanmore BR. Fuel 2003;82:715-20.

[32] Ye DP, Agnew JB, Zhang DK. Fuel 1998;77:1209-19.

[33] Wu Z, Sugimoto Y, Kawashima H. Fuel 2003;82:2057-64.

[34] Samaras P, Diamadopoulos E, Sakellaropoulos GP. Fuel 1996;75: 1108-14.

[35] Erincin D, Sinag A, Misirlioglu Z, Canel M. Energy Convers Manage 2005;46:2748-61.

[36] Iniesta E, Sanchez F, Garcia AN, Marcilla A. J Anal Appl Pyrolysis 2001; 58-59:983-94. 